SUPPORTING INFORMATION

\title{
Vanillin-based Resin for Additive Manufacturing
}

Alexander W. Bassett, ${ }^{\dagger}$ Amy E. Honnig, ${ }^{\dagger}$ Claire M. Breyta, ${ }^{\dagger}$ Ian C. Dunn, ${ }^{\dagger}$ John J. La Scala, $\ddagger$ Joseph F. Stanzione, I/I*⿻

†Department of Chemical Engineering, Rowan University, 201 Mullica Hill Rd., Glassboro, NJ 08028, United States

‡Combat Capabilities Development Command - Army Research Laboratory, 4600 Deer Creek Loop, Aberdeen Proving Ground, MD 21005, United States

Correspondence to: Joseph F. Stanzione, III (stanzione@rowan.edu)

Total Number of Pages: 4

Total Number of Figures: 3

Total Number of Tables: 1 


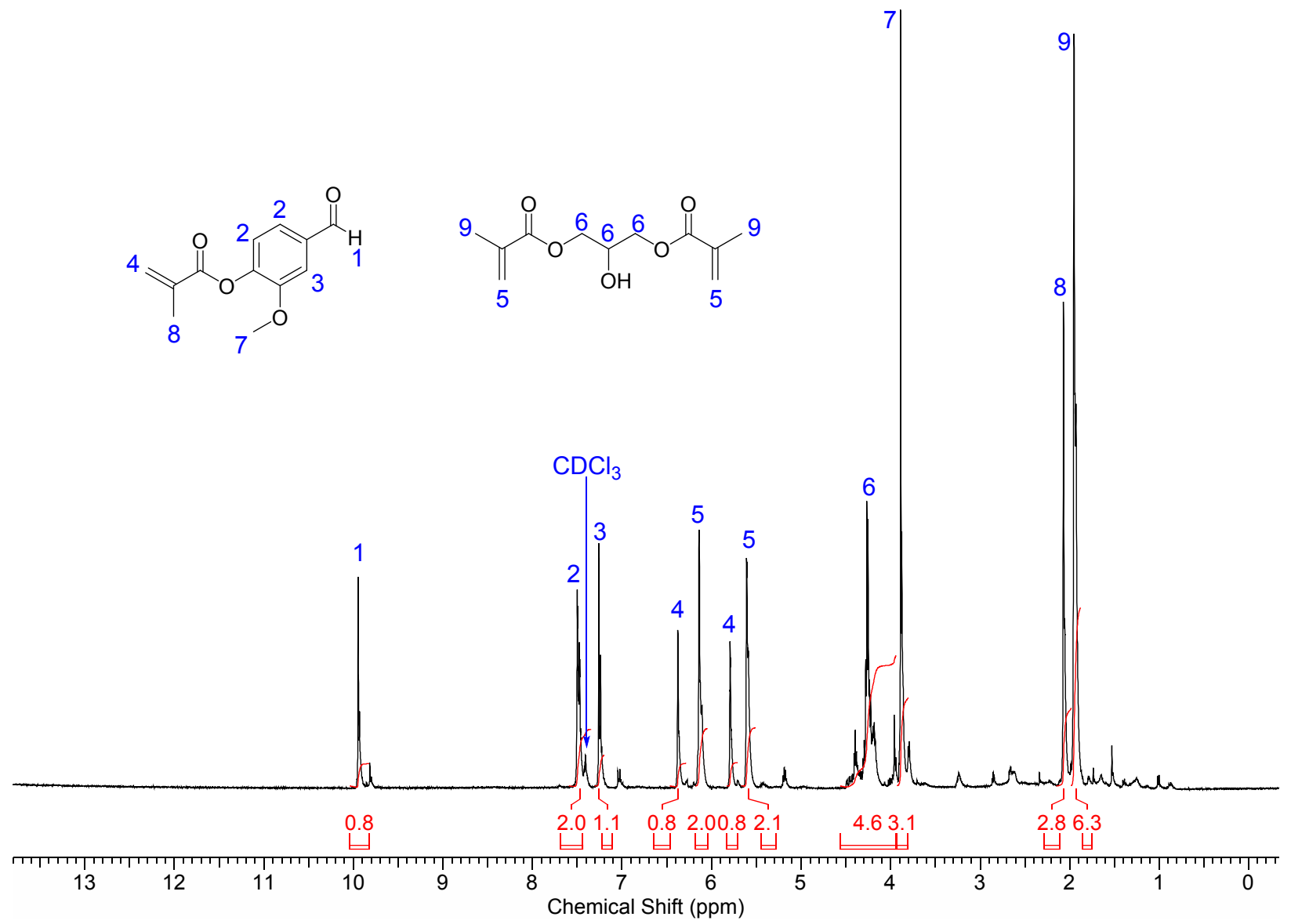

Figure S1. ${ }^{1} \mathrm{H}-\mathrm{NMR}$ spectrum of the 1P2S MV-GMA resin. 


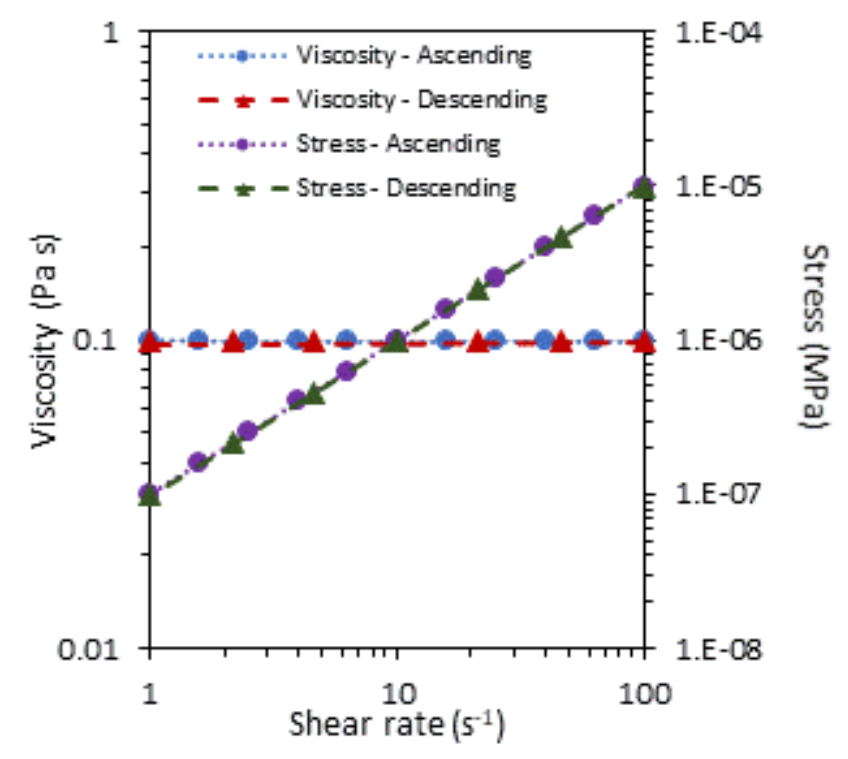

Figure S2. 1P2S MV-GMA resin viscosity as a function of shear rate.

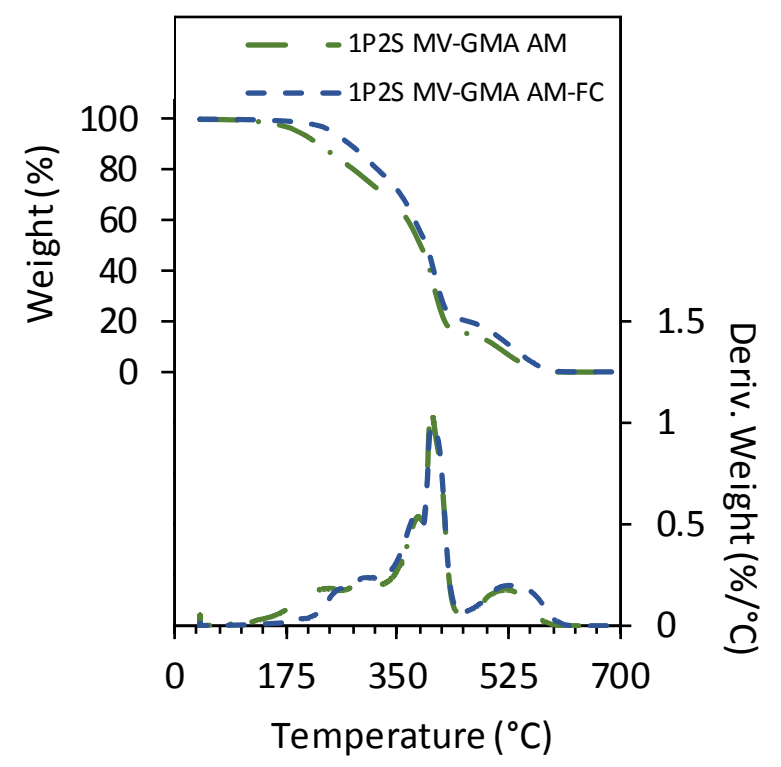

Figure S3. TGA thermograms and the respective 1st derivatives of the 1P2S MV-GMA AM and form cured samples in air. 
Table S1. Thermogravimetric properties for the 1P2S MV-GMA AM and FC in air.

\begin{tabular}{|c|c|c|c|c|}
\hline System & $\begin{array}{l}\text { IDT } \\
\left({ }^{\circ} \mathrm{C}\right)\end{array}$ & $\begin{array}{l}\mathbf{T}_{50 \%} \\
\left({ }^{\circ} \mathrm{C}\right)\end{array}$ & $\begin{array}{l}\mathbf{T}_{\max } \\
\left({ }^{\circ} \mathrm{C}\right)\end{array}$ & $\begin{array}{c}\text { Char } \\
\text { Content } \\
(\%)\end{array}$ \\
\hline 1P2S MV-GMA AM & $198 \pm 7$ & $389 \pm 2$ & $402 \pm 1$ & $0.2 \pm 0.1$ \\
\hline 1P2S MV-GMA AM-FC & $245 \pm 4$ & $395 \pm 1$ & $403 \pm 1$ & $0.3 \pm 0.1$ \\
\hline
\end{tabular}

